\title{
Efficiency of a gas diffuser and influence of suction in carbon dioxide deairing of a cardiothoracic wound cavity model
}

Peter Svenarud, MD, ${ }^{a}$ Mikael Persson, $\mathrm{MSc}^{\mathrm{a}}{ }^{\mathrm{ab}}$ and Jan van der Linden, $\mathrm{MD}, \mathrm{PhD}^{\mathrm{a}}$
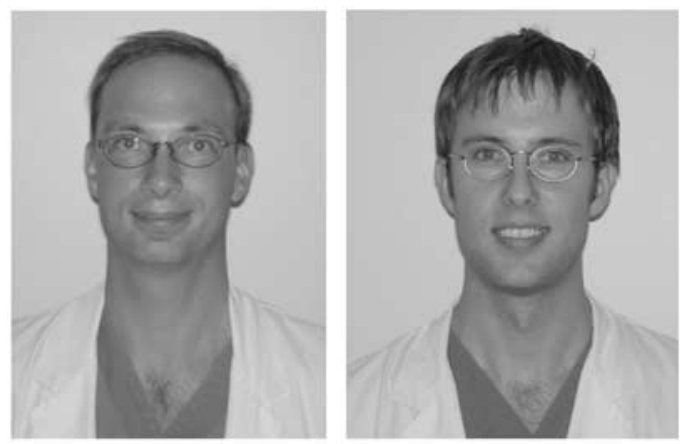

Objective: In cardiac surgery, insufflation of carbon dioxide is used for deairing of the heart and great vessels. The aim of this study was to assess a new insufflation device for efficient deairing and to study the influence of suction.

Methods: We measured the content of remaining air at two positions in the cardiothoracic wound model. A new insufflation device, a gas diffuser, was compared with a conventional 0.25 -inch tube. Carbon dioxide flow (5 and $10 \mathrm{~L} / \mathrm{min})$ and suction $(0,1.5,10$, and $25 \mathrm{~L} / \mathrm{min})$ were varied. Suction was studied in combination with the gas diffuser.

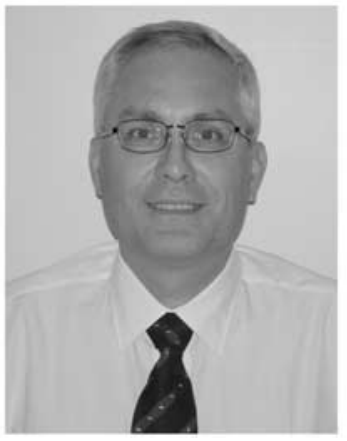

P. Svenarud, M. Persson, J. van der Linden
Results: With the tube the median air content in the wound model was $19.5 \%$ to $51.7 \%$ at the studied carbon dioxide flows, whereas with the gas diffuser the median air content was no greater than $1.2 \%$ at $5 \mathrm{~L} / \mathrm{min}$ and no greater than $0.31 \%$ at 10 $\mathrm{L} / \mathrm{min}(P<.001)$. When suction of $1.5 \mathrm{~L} / \mathrm{min}$ was applied, the median air content in the model remained low $(\leq 1.0 \%)$ at both carbon dioxide flows. With suction of $10 \mathrm{~L} / \mathrm{min}$ the median air content was still low $(\leq 0.50 \%)$ at a simultaneous carbon dioxide flow of $10 \mathrm{~L} / \mathrm{min}$. Conversely, suction of $25 \mathrm{~L} / \mathrm{min}$ caused a marked increase in air content at carbon dioxide flows of both 5 and $10 \mathrm{~L} / \mathrm{min}(P<.001)$.

Conclusions: This study demonstrated that the most efficient deairing ( $\leq 1 \%$ remaining air) in a cardiothoracic wound model was provided by a gas diffuser at a carbon dioxide flow of $10 \mathrm{~L} / \mathrm{min}$. A conventional 0.25 -inch tube failed to do so (19.5\%-51.7\% remaining air). Additional suction deteriorated air displacement with the gas diffuser when suction exceeded carbon dioxide inflow.

\footnotetext{
From the Department Cardiothoracic Surgery and Anesthesiology, Huddinge University Hospital, ${ }^{\mathrm{a}}$ and the Division of Medical Engineering, Department of Medical Laboratory Science and Technology, Karolinska Institute, ${ }^{\mathrm{b}}$ Stockholm, Sweden.

Supported by Karolinska Institute and Cardia Innovation AB, Stockholm, Sweden.

Received for publication June 14, 2002; accepted for publication Aug 6, 2002

Address for reprints: Jan van der Linden, MD, Department of Cardiothoracic Surgery and Anesthesiology, M85, Karolinska Institute, Huddinge University Hospital, SE-141 86 Stockholm, Sweden (E-mail: jan.vanderlinden@thsurg.hs.sll.se).

J Thorac Cardiovasc Surg 2003;125:1043-9

Copyright $(\odot) 2003$ by The American Association for Thoracic Surgery

$0022-5223 / 2003 \$ 30.00+0$

doi: $10.1067 / \mathrm{mtc} .2003 .50$
}

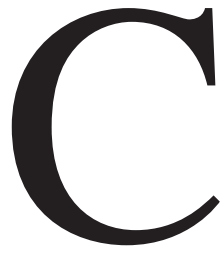

erebral injury, myocardial dysfunction, and arrhythmia as a result of arterial air embolism are feared complications in cardiac surgery. ${ }^{1-7}$ Even if standard deairing techniques are meticulously followed, large air emboli may still occur. ${ }^{8,9}$ Carbon dioxide insufflated into the chest wound cavity is held to improve the deairing, because carbon dioxide is at least 25 times more soluble in blood and tissue than room air. ${ }^{10,11}$ Arterial carbon dioxide emboli are therefore much better tolerated than are air emboli..$^{2-5,12,13}$ Furthermore, carbon dioxide is 50\% heavier than air, which facilitates air displacement in a cavity. Although carbon dioxide has been used for deairing in cardiac surgery during the last 50 years, its use is not widespread. The wound cavity is usually insufflated with carbon dioxide through an open-ended tube, but the ability of this procedure to provide efficient air displacement in the wound cavity has recently been questioned. ${ }^{14}$

Several important factors influence carbon dioxide deairing during cardiac surgery, such as type of insufflation device, carbon dioxide flow, and coronary and rough suction. These factors were controlled in this study.

The first aim of this study was to assess a new carbon dioxide insufflation device at different carbon dioxide flows for air displacement in a cardiothoracic wound 
cavity model, where a conventional open-ended tube served as a control. A second aim was to study the influence of suction on air displacement in the same model.

\section{Materials and Methods}

\section{Insufflation Devices}

The new patented insufflation device, the gas-diffuser (Cardia Innovation $\mathrm{AB}$, Stockholm, Sweden), consists of a fixable polyvinyl chloride tube with inner diameter $2.5 \mathrm{~mm}$ and a soft cellular polyurethane diffuser $(14 \times 18 \mathrm{~mm})$ attached to the end of the tube. An open-ended tube with an inner diameter of 0.25 inches $(6.35 \mathrm{~mm})$ served as a control.

\section{Instrumentation}

The carbon dioxide flow was measured with a back pressurecompensated oxygen flowmeter, because a flowmeter for medical carbon dioxide was unavailable at the time of the study. The oxygen reading scale was adjusted for carbon dioxide with a universal flowmeter (ABB/Fisher \& Porter, Göttingen, Germany) because of the higher density of carbon dioxide gas. The universal flowmeter consisted of a measuring tube (FP -16 G-5/81) with a spherical stainless steel float (SS-14). The universal flowmeter was not used for measurements in the study because of its lack of back-pressure compensation. This problem was avoided during the calibration by measuring the carbon dioxide outflow distal to the end of the insufflation device. The reading scale of the universal flowmeter was calculated for the used gas (medical carbon dioxide; AGA Gas AB, Stockholm, Sweden) at $20^{\circ} \mathrm{C}$ and at $1013 \mathrm{mbar}$ with a computer program (FlowSelect version 2.0; ABB/Fisher \& Porter).

Coronary suction, which is usually set at an effect of 1 to 1.5 $\mathrm{L} / \mathrm{min}$, was set at $1.5 \mathrm{~L} / \mathrm{min}$ and was provided by a standard roller pump and calibrated according to the manual of the manufacturer (CAPS; Stöckert Instrumente $\mathrm{GmbH}$, Munich, Germany). The rough suction was set at 10 and $25 \mathrm{~L} / \mathrm{min}$ (maximum) and was controlled by two flowmeters with regulators coupled in parallel. These flowmeters were also calibrated with the universal flowmeter.

The degree of air displacement in the wound cavity model was assessed by analyzing the remaining air content (\%Air), which is given by the following equation:

$$
\% \text { Air }=\frac{\% \mathrm{O}_{2}}{\% \mathrm{O}_{2}(\mathrm{ref})} \times 100 \%
$$

where $\% \mathrm{O}_{2}$ is the measured oxygen concentration and $\% \mathrm{O}_{2}(r e f)$ is the oxygen concentration in atmospheric air near sea level $(20.95 \%){ }^{15}$ The oxygen content was measured with an oxygen sensor (CheckMate 9900; PBI-Dansensor A/S, Ringsted, Denmark), which has a gas sampling volume of less than $2 \mathrm{~mL}$, a response time of $<2$ seconds ( $>20.95 \%$ change in oxygen concentration in both directions), a range of measurement of $0.0001 \%$ to $100 \%$ oxygen, and an accuracy of $1 \%$ of the measured value. The sampling probe was a $1.5 \mathrm{~mm}$ thick polytetrafluoroethylene tube. The oxygen instrument was connected to a personal computer for recording of data.

\section{Setup}

The degree of air displacement was studied in an anatomic torso model with an open cardiothoracic wound containing a silicone replica of the heart and great vessels. The shape of the model was based on the maximal measurements of the open chest wounds of five adults undergoing cardiac surgery (standard sternotomy and during cardiopulmonary bypass with empty heart). We presupposed that a wound cavity with a large opening would be more difficult to deair because of increased diffusion. The torso was placed on the operating table of an operating theater normally ventilated for cardiac surgery (downward laminar airflow from the ceiling above the operating table, approximately $2500 \mathrm{~m}^{3} / \mathrm{h}$ ). The wound opening was $20 \mathrm{~cm}$ long (midline) and $12 \mathrm{~cm}$ wide. The volume of the wound cavity without the artificial heart was $2.5 \mathrm{~L}$. The external volume of the artificial heart, including the great vessels, was $1.0 \mathrm{~L}$ giving a residual cavity volume of $1.5 \mathrm{~L}$. The orifices of the insufflation devices were positioned $5 \mathrm{~cm}$ below the wound opening adjacent to the diaphragm. The tube was pointed toward the center of the wound cavity and not toward the site of measurements. Carbon dioxide was insufflated into the wound cavity at flows of 5 and $10 \mathrm{~L} / \mathrm{min}$. The remaining air content was measured at the highest part of the right atrium, $5 \mathrm{~cm}$ below the wound opening, and at the highest part of the ascending aorta, 3 $\mathrm{cm}$ below the wound opening. These positions are close to the sites of the atrial and aortic incisions in valve surgery.

\section{Measurements}

First, the air displacement efficiencies of the two insufflation devices were assessed without suction. A stable oxygen concentration was considered to be present when values were fluctuating around a constant value through a period of 30 seconds. Thereafter the oxygen concentration was recorded 10 times in succession, once every 5 seconds $(n=10)$. The efficiency of the gas diffuser was further studied with the addition of the varying degrees of continuous suction $(1.5,10$, and $25 \mathrm{~L} / \mathrm{min})$ at the site of the artificial left atrial appendage. When a stable oxygen concentration, as defined previously, was present, suction was applied and the oxygen concentration was recorded once every 5 seconds during 60 seconds. Each recording procedure with suction was repeated 10 times $(\mathrm{n}=10)$. At all measurements the remaining carbon dioxide in the model was removed with the rough sucker before every change of carbon dioxide flow or insufflation device. Thereafter air movements around the model were left to settle for 1 minute.

\section{Statistics}

This was an analysis of variance design, but because of unsuitable distribution characteristics a more simple and conservative nonparametric analysis was chosen. Mann-Whitney $U$ tests and Wilcoxon tests were used whenever appropriate. Data in the diagrams are presented as median and range.

\section{Results}

Figure 1 depicts the remaining air content at the right atrium and at the ascending aorta when the wound model was insufflated with carbon dioxide at flows of 5 and $10 \mathrm{~L} / \mathrm{min}$ through the 0.25 -inch tube and the gas diffuser. With the 
A

Right Atrium

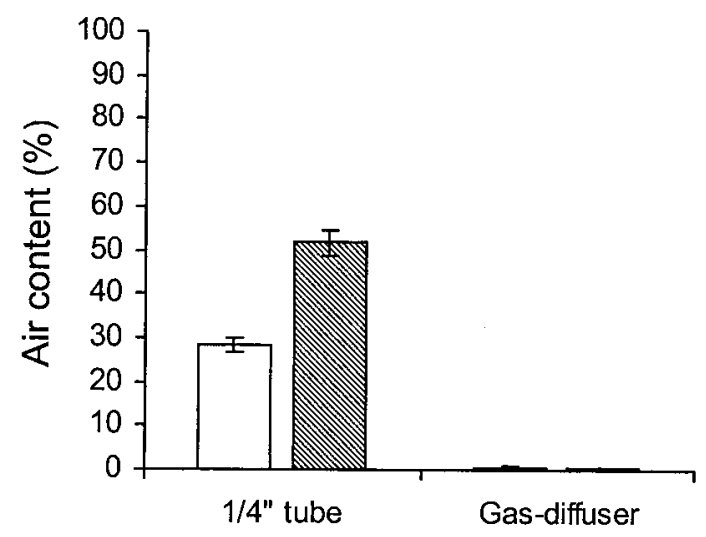

\author{
$\square \mathrm{CO} 2$ flow $5 \mathrm{l} / \mathrm{min}$ \\ $\mathbb{B} \mathrm{CO} 2$ flow $10 \mathrm{l} / \mathrm{min}$
}

B

Ascending Aorta

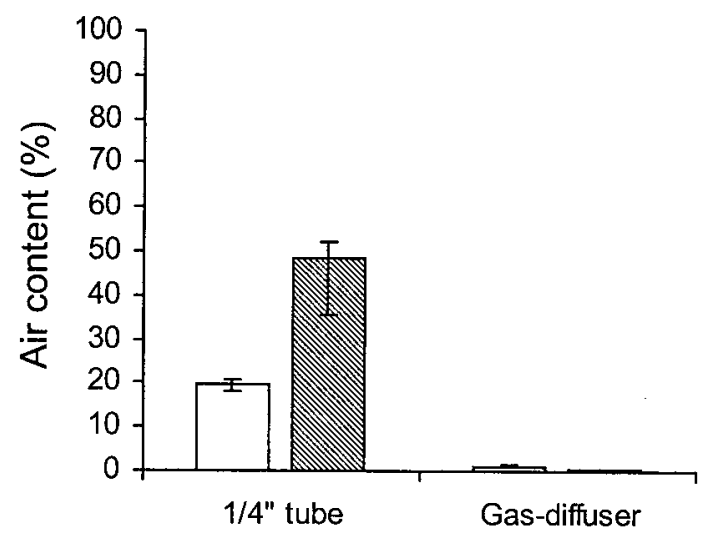

$\square \mathrm{CO} 2$ flow $5 \mathrm{l} / \mathrm{min}$

$\mathbb{} \mathrm{CO} 2$ flow $10 \mathrm{l} / \mathrm{min}$

Figure 1. Air contents $(n=10)$ at right atrium $(A)$ and at ascending aorta $(B)$ when cardiothoracic wound model was continuously insufflated with carbon dioxide at flows of $5 \mathrm{~L} / \mathrm{min}$ (white bars) and $10 \mathrm{~L} / \mathrm{min}$ (shaded bars) through 0.25-inch tube and gas diffuser. Bar heights represent median; error bars represent range.

0.25 -inch tube the median air contents at the right atrium were $28.3 \%$ (range $26.9 \%-30.0 \%$ ) and $51.7 \%$ (range $48.5 \%$ $54.6 \%, P<.001)$ at carbon dioxide flows of 5 and 10 $\mathrm{L} / \mathrm{min}$, respectively. The corresponding values at the ascending aorta were $19.5 \%$ (range $18.1 \%-20.5 \%$ ) and $48.2 \%$ (range $35.4 \%-52.1 \%, P<.001$ ). The air content was lower at the ascending aorta than at the right atrium with carbon dioxide flows of both $5 \mathrm{~L} / \mathrm{min}(P<.001)$ and $10 \mathrm{~L} / \mathrm{min}$ $(P<.01)$. With the gas diffuser the median air content at the right atrium decreased from $0.65 \%$ (range $0.54 \%-1.3 \%$ ) at a carbon dioxide flow of $5 \mathrm{~L} / \mathrm{min}$ to $0.29 \%$ (range $0.27 \%-0.33 \%, P<.001)$ at $10 \mathrm{~L} / \mathrm{min}$. The corresponding values at the ascending aorta were $1.2 \%$ (range $0.88 \%$ $1.4 \%$ ) and $0.31 \%$ (range $0.24 \%-0.36 \%, P<.001$ ). The air content was lower at the right atrium than at the ascending aorta at a carbon dioxide flow of $5 \mathrm{~L} / \mathrm{min}(P=.002)$. With a carbon dioxide flow of $10 \mathrm{~L} / \mathrm{min}$ there was no statistical difference in air content between the two positions. The air content was markedly lower with the gas diffuser than with the 0.25 -inch tube $(P<.001)$ for both carbon dioxide flows both at the right atrium and at the ascending aorta.

Figure 2 illustrates the remaining air content at the right atrium and at the ascending aorta after 1 minute of varying degrees of continuous suction when the cavity was insufflated at carbon dioxide flows of 5 and $10 \mathrm{~L} / \mathrm{min}$ with the gas diffuser. A carbon dioxide flow of $10 \mathrm{~L} / \mathrm{min}$ resulted in a lower air content than did a carbon dioxide flow of 5 $\mathrm{L} / \mathrm{min}$ for all degrees of suction both at the right atrium and at the ascending aorta $(P<.001)$. The median air content remained low $(\leq 0.24 \%$ at $10 \mathrm{~L} / \mathrm{min}$ carbon dioxide and $\leq 1.0 \%$ at $5 \mathrm{~L} / \mathrm{min}$ carbon dioxide) both at the right atrium and at the ascending aorta when a suction of $1.5 \mathrm{~L} / \mathrm{min}$ was applied. With a carbon dioxide flow of $10 \mathrm{~L} / \mathrm{min}$ the air content was lower than in the case when no suction was 


\section{A. \\ Right Atrium}

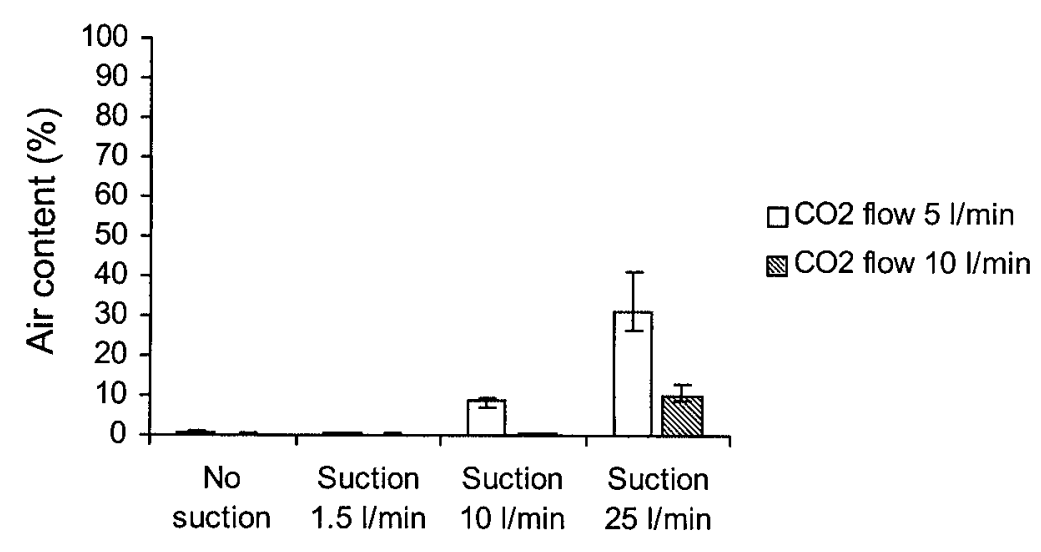

B

Ascending Aorta

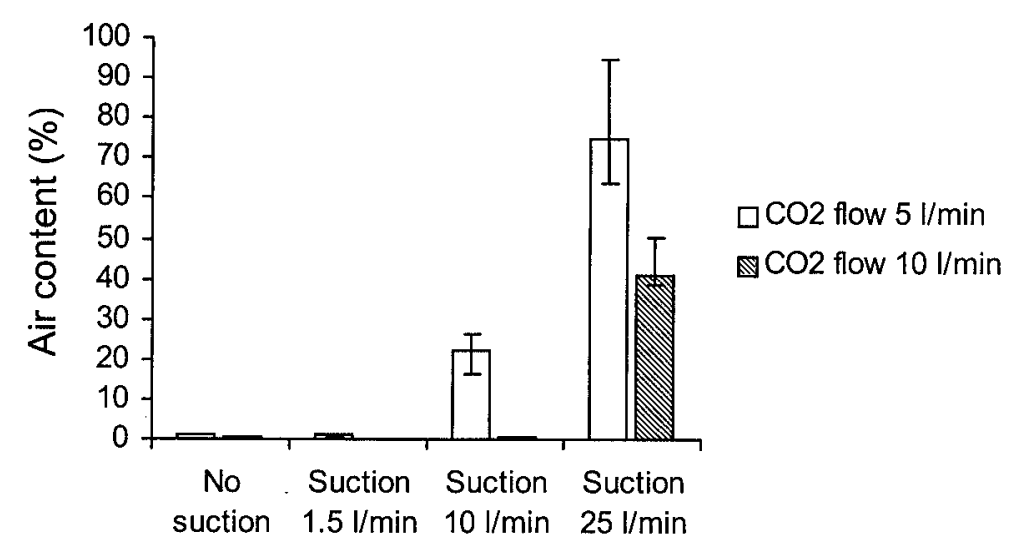

Figure 2. Air contents $(n=10)$ at right atrium $(A)$ and at ascending aorta $(B)$ in cardiothoracic wound model after 1 minute of various degrees of continuous suction at left atrial appendage. Carbon dioxide was supplied at flows of $5 \mathrm{~L} / \mathrm{min}$ (white bars) and $10 \mathrm{~L} / \mathrm{min}$ (shaded bars) through gas diffuser. Bar heights represent median; error bars represent range.

used both at the right atrium $(P=.001)$ and at the ascending aorta $(P<.001)$. With a suction of $10 \mathrm{~L} / \mathrm{min}$ the median air content was still low both at the right atrium $(0.37 \%)$ and at the ascending aorta $(0.50 \%)$ with a simultaneous carbon dioxide flow of $10 \mathrm{~L} / \mathrm{min}$ but much higher $(>8.9 \%, P<$ .001 ) at both sites with a carbon dioxide flow of $5 \mathrm{~L} / \mathrm{min}$. A suction of $25 \mathrm{~L} / \mathrm{min}$ increased the median air content at the right atrium to $9.9 \%(P<.001)$ at a carbon dioxide flow of $10 \mathrm{~L} / \mathrm{min}$ and to $31.4 \%(P<.001)$ at a flow of $5 \mathrm{~L} / \mathrm{min}$. The corresponding values at the ascending aorta were $41.1 \%(P<$ $.001)$ and $75.1 \%(P<.001)$. With suctions of 10 and $25 \mathrm{~L} / \mathrm{min}$ the air content at the right atrium was lower than at the ascending aorta at both carbon dioxide flows $(P=.001)$.

Figure 3 depicts the air content at the right atrium and at the ascending aorta during the first 30 seconds of continuous suction at 10 and $25 \mathrm{~L} / \mathrm{min}$ when the cavity was insufflated at a carbon dioxide flow of $10 \mathrm{~L} / \mathrm{min}$ with the gas diffuser. At a suction of $10 \mathrm{~L} / \mathrm{min}$ the median air content remained low $(\leq 0.46 \%)$ both at the right atrium and at the ascending aorta during the measurements. After the start of suction with $25 \mathrm{~L} / \mathrm{min}$, the air content remained unchanged during 5 seconds at both sites, followed by an increase after 10 seconds. Stable air contents were reached after 15 and 20 seconds at the right atrium and at the ascending aorta, respectively, with a higher air content at the ascending aorta than at the right atrium $(P<.001)$.

\section{Discussion}

\section{Experimental Design}

The size and form of the wound model were based on in vivo measurements. We therefore feel justified in assuming that the model enabled us to perform a controlled and 
A

Right Atrium

$\mathrm{CO}_{2}$ flow $10 \mathrm{l} / \mathrm{min}$

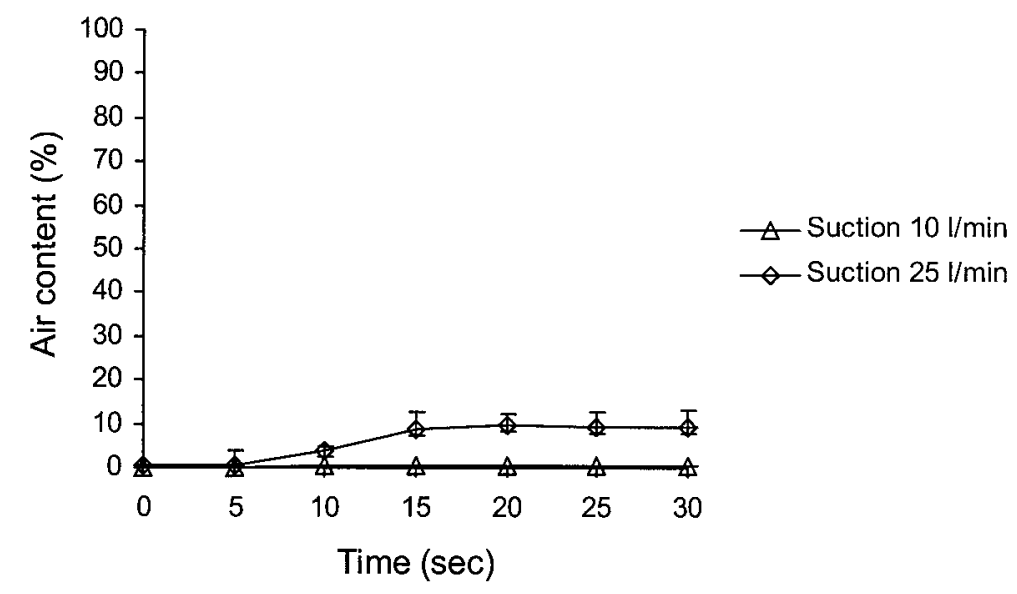

B

Ascending Aorta

$\mathrm{CO}_{2}$ flow $10 \mathrm{l} / \mathrm{min}$

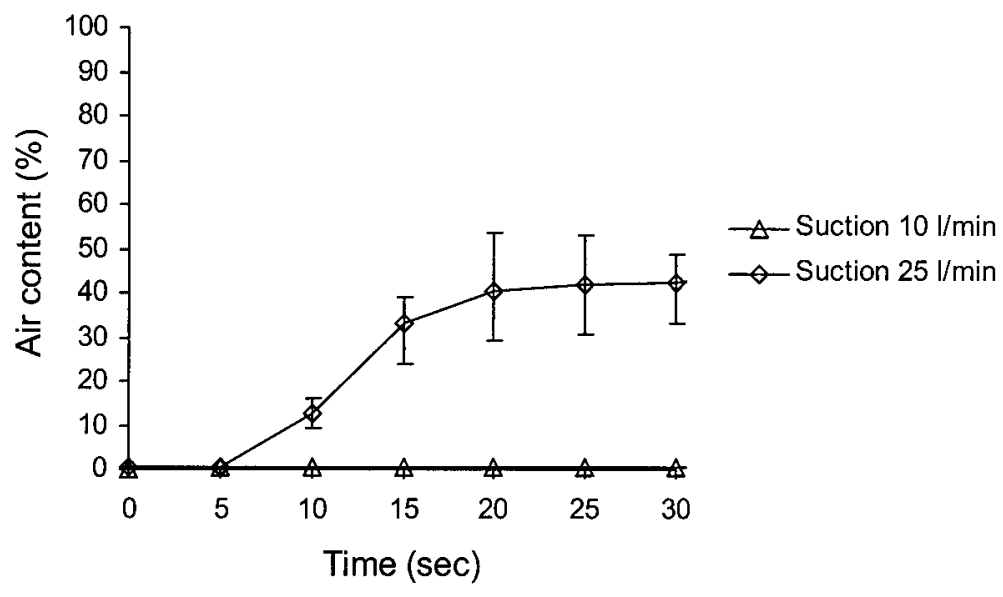

Figure 3. Air contents $(n=10)$ at right atrium $(A)$ and at ascending aorta $(B)$ in cardiothoracic wound model during 30 seconds of continuous suction at $10 \mathrm{~L} / \mathrm{min}$ (triangles) and $25 \mathrm{~L} / \mathrm{min}$ (diamonds). Carbon dioxide was insufflated at flow of $10 \mathrm{~L} / \mathrm{min}$ with gas diffuser. Data points represent median; error bars represent range.

standardized study of air displacement with carbon dioxide insufflation in a realistic clinical setup. Measurements were carried out on the same operating table in the same fully ventilated operating theater as part of our efforts to reproduce the conditions existing in practice as carefully as possible.

Measuring the content of carbon dioxide or air ${ }^{11,16}$ in a cardiothoracic wound cavity may assess the degree of air displacement. In this study the air content was estimated by measuring the oxygen concentration, which is $20.95 \%$ in atmospheric air near sea level. ${ }^{15}$ The instrument that was used, an oxygen sensor with a heated ceramic element, can assess air displacement more accurately and faster than can commonly used carbon dioxide sensors that use an optical infrared sensor technique to measure $0 \%$ to $100 \%$ carbon dioxide. The oxygen sensor's accuracy was $1 \%$ of the measured value in the range $0.0001 \%$ to $100 \%$ oxygen, which means that the accuracy increases as the oxygen and the air contents decrease. Moreover, the oxygen sensor requires only a $2-\mathrm{mL}$ gas sample volume and has a response time of less than 2 seconds. The smaller the gas sample needed, the shorter is the response time and the less will gas 
measurements interfere with carbon dioxide deairing. In contrast, carbon dioxide sensors that use the infrared technique usually have a constant accuracy of approximately $\pm 2 \%$ carbon dioxide across the entire range of measurement of $0 \%$ to $100 \%$ carbon dioxide, a larger required sampling volume, and a longer response time, usually longer than 10 seconds. The fast response modality of the oxygen sensor used enabled us to detect rapid variations of air content with time. Thus we consider the oxygen sensor that we used more suitable for evaluation of low air contents during steady state and during changes than optical infrared carbon dioxide sensors would be.

Because only carbon dioxide flows of $10 \mathrm{~L} / \mathrm{min}$ or less have so far been reported, ${ }^{3,11,14,16-20}$ we did not study carbon dioxide flows higher than $10 \mathrm{~L} / \mathrm{min}$. Moreover at $5 \mathrm{~L} / \mathrm{min}$ almost complete air displacement was already obtained when the gas diffuser was used.

\section{Carbon Dioxide Insufflation Devices}

We studied an open-ended tube with an inner diameter of 0.25 inches because tubes of the same size have been used for carbon dioxide insufflation in our clinic as well as in earlier studies. ${ }^{11,16,20}$ In this study the air displacement efficiency of the 0.25 -inch tube was compared with a new device, a gas diffuser. The study revealed a striking difference in efficiency between the conventional 0.25 -inch openended tube and the gas diffuser at the studied carbon dioxide flows (Figure 1). Carbon dioxide insufflation with the 0.25inch tube resulted in median air contents between 19.5\% and $28.3 \%$ and between $48.2 \%$ and $51.7 \%$ at carbon dioxide flows of 5 and $10 \mathrm{~L} / \mathrm{min}$, respectively. The insufficient air displacement with the 0.25 -inch tube worsened with increased carbon dioxide flow. The 0.25 -inch tube's apparent failure to displace air with carbon dioxide was probably due to the turbulence induced by the carbon dioxide jet. The same phenomenon occurs when one tries to fill a pail with water by means of a garden hose. Most of the water splashes out of the pail. By contrast, the pail is quickly filled if the hose is provided with a multi-perforated nozzle, resulting in a reduced flow velocity. With the gas diffuser the median air content was no greater than $1.2 \%$ at $5 \mathrm{~L} / \mathrm{min}$ and no greater than $0.31 \%$ at $10 \mathrm{~L} / \mathrm{min}$, which indicates minimal turbulence despite a high carbon dioxide flow.

\section{Suction and Carbon Dioxide Flow}

The influence of suction has to be considered when aiming at efficient deairing with carbon dioxide insufflation in cardiac surgery. Coronary suction of $1.5 \mathrm{~L} / \mathrm{min}$ did not deteriorate air displacement in the wound cavity. In vivo, however, continuous suction of almost pure carbon dioxide into the cardiotomy reservoir may affect arterial $\mathrm{pCO}_{2} \cdot{ }^{17,19,20}$ This may be avoided by minimizing continuous suction of carbon dioxide and by increasing the ventilation of the oxygenator. A rough suction of $25 \mathrm{~L} / \mathrm{min}$ applied in the wound cavity at carbon dioxide flows of 5 and $10 \mathrm{~L} / \mathrm{min}$ markedly increased the air content. This was to be expected because the suction markedly exceeded the carbon dioxide inflow. Surprisingly, the air content did not rise toward $100 \%$ but stabilized at lower levels. This may be explained by a partial suction of air from above the cavity. In addition, carbon dioxide disperses effectively from the diffuser in multiple directions in the wound cavity and not only toward the suction. The increase of air content to a stable level started first after 5 seconds and before 10 seconds of suction (not adjusted for the response time of the instrument, which is $<2$ seconds). This delay is most likely explained by the buffering effect of the volume of carbon dioxide within the cavity. A smaller wound cavity will hold a smaller volume of carbon dioxide, which may make it more difficult to keep a low air content when suction is applied. When the rough suction was reduced to equal the carbon dioxide inflow at 10 $\mathrm{L} / \mathrm{min}$, the median air content could be kept at no higher than $0.5 \%$ in the wound cavity.

These findings suggest that the duration of active use of rough suction at $25 \mathrm{~L} / \mathrm{min}$ is important if it is higher than the carbon dioxide flow. A short period of suction, up to approximately 5 seconds, does not affect the air content, whereas a longer period of suction creates an increase in the air content, which soon stabilizes. Thus rough suction should be kept as short as possible when used actively inside the wound cavity, provided that it is not continuously sucking fluid. Otherwise the suction should either be shut off or be kept outside the wound cavity. ${ }^{11}$ Another option is to set the rough suction equal to or lower than the carbon dioxide inflow. Theoretically the carbon dioxide flow could also be increased to $25 \mathrm{~L} / \mathrm{min}$, but this may not be necessary, because as a rule rough suction is only used infrequently and during short periods.

\section{When and Where to Insufflate Carbon Dioxide}

The wound cavity should be insufflated with carbon dioxide when there is a risk of air entering the circulatory system. If air enters the heart and great vessels, air may be trapped ${ }^{21}$ and sooner or later embolize. ${ }^{8,9}$ It is important that carbon dioxide is insufflated from incision to closure of the heart and great vessels so that these potential air pockets are filled with carbon dioxide. This is relevant not only for heart and aortic surgery but also when the single-clamp technique is used in conventional coronary artery bypass surgery.

The gas diffuser is preferably placed where it is efficient without interfering with surgery. In this study the diffuser was positioned $5 \mathrm{~cm}$ below the opening, adjacent to the diaphragm. During surgery there is little activity at this site, and few if any surgical instruments are present. At this position the gas diffuser provided a high degree of air displacement both at the site of the right atrium and at the ascending aorta. When suction exceeds carbon dioxide in- 
flow, however, the proximity of the diffuser to the location of interest (measuring point) becomes important for air displacement (Figure 2 and 3).

\section{Conclusions}

This study demonstrated that at a carbon dioxide flow of 10 $\mathrm{L} / \mathrm{min}$ the gas diffuser provided efficient air displacement ( $\leq 1 \%$ remaining air) in a cardiothoracic wound cavity model. By contrast, a conventional 0.25 -inch tube failed to do so (19.5\%-51.7\% remaining air). Coronary suction did not influence carbon dioxide deairing. Rough suction deteriorated air displacement with the gas diffuser when suction exceeded carbon dioxide inflow, only then making the proximity of the gas diffuser to the location of interest important.

Magnus Backheden MSc, Section of Medical Statistics, Department of Humanities, Informatics and Social Sciences, Karolinska Institute, Stockholm, Sweden, reviewed the statistical analysis.

\section{References}

1. Fries CC, Levowitz B, Adler S, Cook AW, Karlson KE, Dennis C. Experimental cerebral air embolism. Ann Surg. 1957;145:461-70.

2. Kunkler A, King H. Comparison of air, oxygen and carbon dioxide embolization. Ann Surg. 1959;149:95-9.

3. Eguchi S, Sakurai Y, Yamaguchi A. The use of carbon dioxide gas to prevent air embolism during open heart surgery. Acta Med Biol. 1963;11:1-13.

4. Goldfarb D, Bahnson HT. Early and late effects on the heart of small amounts of air in the coronary circulation. J Thorac Cardiovasc Surg. 1963;46:368-78.

5. Spencer FC, Rossi NP, Yu S-C, Koepke JA. The significance of air embolism during cardiopulmonary bypass. J Thorac Cardiovasc Surg. 1965;49:615-34.

6. Hindman BJ, Dexter F, Subieta A, Smith T, Cutkomp J. Brain injury after cerebral arterial air embolism in the rabbit as determined by triphenyltetrazolium staining. Anesthesiology. 1999;90:1462-73.
7. Borger MA, Peniston CM, Weisel RD, Vasiliou M, Green RE, Feindel CM. Neuropsychologic impairment after coronary bypass surgery: effect of gaseous microemboli during perfusionist interventions. J Thorac Cardiovasc Surg. 2001;121:743-9.

8. van der Linden J, Casimir-Ahn H. When do cerebral emboli appear during open heart operations? A transcranial Doppler study. Ann Thorac Surg. 1991;51:237-41.

9. Tingleff J, Joyce FS, Pettersson G. Intraoperative echocardiographic study of air embolism during cardiac operations. Ann Thorac Surg. 1995;60:673-7.

10. Mitz MA. $\mathrm{CO}_{2}$ biodynamics: a new concept of cellular control. $J$ Theor Biol. 1979;80:537-51.

11. Ng SW, Rosen M. Carbon dioxide in the prevention of air embolism during open-heart surgery. Thorax. 1968;23:194-6.

12. Eguchi S, Bosher LH Jr. Myocardial dysfunction resulting from coronary air embolism. Surgery. 1962;51:103-11.

13. Moore RM, Braselton CW Jr. Injection of air and of carbon dioxide into a pulmonary vein. Ann Surg. 1940;112:212-8.

14. Martens S, Dietrich M, Wals S, Steffen S, Wimmer-Greinecker G, Moritz A. Conventional carbon dioxide application does not reduce cerebral or myocardial damage in open heart surgery. Ann Thorac Surg. 2001;72:1940-4.

15. Lindsay B. Mechanics. In: Gray DE, editor. American Institute of Physics handbook. 3rd ed. New York: McGraw-Hill; 1972. p. 134.

16. Selman MW, McAlpine WA, Albregt H, Tatan R. An effective method of replacing air in the chest with $\mathrm{CO}_{2}$ during open-heart surgery. J Thorac Cardiovasc Surg. 1967;53:618-22.

17. Burbank A, Ferguson TB, Burford TH. Carbon dioxide flooding of the chest in open-heart surgery: a potential hazard. J Thorac Cardiovasc Surg. 1965;50:691-8.

18. Olinger GN. Carbon dioxide displacement of left heart chambers. J Thorac Cardiovasc Surg. 1995;109:187-8.

19. O'Connor BR, Kussman BD, Park KW. Severe hypercarbia during cardiopulmonary bypass: a complication of $\mathrm{CO}_{2}$ flooding of the surgical field. Anesth Analg. 1998;86:264-6.

20. Nadolny EM, Svensson LG. Carbon dioxide field flooding techniques for open heart surgery: monitoring and minimizing potential adverse effects. Perfusion. 2000;15:151-3.

21. Orihashi K, Matsuura Y, Hamanaka Y, Sueda T, Shikata H, Hayashi $\mathrm{S}$, et al. Retained intracardiac air in open heart operations examined by transesophageal echocardiography. Ann Thorac Surg. 1993;55:146771.

\section{Bound volumes available to subscribers}

Bound volumes of The Journal of Thoracic and Cardiovascular Surgery are available to subscribers (only) for the 2003 issues from the Publisher, at a cost of $\$ 134.00$ for domestic, $\$ 165.85$ for Canadian, and $\$ 155.00$ for international subscribers for Vol 125 (January-June) and Vol 126 (July-December). Shipping charges are included. Each bound volume contains a subject and author index and all advertising is removed. The binding is durable buckram with the Journal name, volume number, and year stamped in gold on the spine. Payment must accompany all orders. Contact Mosby, Subscription Customer Service, 6277 Sea Harbor Dr, Orlando, FL 32887, USA; phone 800-654-2452 or 407-345-4000.

Subscriptions must be in force to qualify. Bound volumes are not available in place of a regular Journal subscription. 